УДК: 616.36-002:616.12-008.331.1

DOI: $10.15587 / 2313-8416.2014 .30424$

\title{
ПОРТАЛЬНЫЙ КРОВОТОК ПРИ НЕАЛКОГОЛЬНОЙ ЖИРОВОЙ БОЛЕЗНИ ПЕЧЕНИ В ДИНАМИКЕ ЛЕЧЕНИЯ
}

\author{
() А. П. Козлов
}

Изучено состояние портальной гемодинамики при неалкогольной жировой болезни печени в сочетании с гипертонической болезнью и ишемической болезнью сердияа в динамике лечения. На фоне комплексной терапии достоверно снижались показатели портосистемного шунтирования, что служило признаком снижения портального давления и препятствовало развитию портопульмонального синдрома

Ключевые слова: неалкогольная жировая болезнь печени, гипертоническая болезнь, ишемическая болезнь сердца, портальный кровоток

The state of portal hemodynamics in non-alcoholic fatty liver disease in combination with hypertension and coronary heart disease during the treatment is investigated. Complex therapy significantly decreased the ratio of portosystemic shunt, which is a sign of decrease in portal pressure and hindered the development of portopulmonary syndrome

Keywords: nonalcoholic fatty liver disease, hypertension, coronary heart disease, portal blood flow

\section{1. Введение}

Неалкогольная жировая болезнь печени (НАЖБП) - это заболевание, которое сопровождается последовательными патологическими изменениями в паренхиме печени на фоне, в первую очередь, синдрома инсулинорезистентности (ИР), и развитием фиброзных изменений в печеночной ткани, которые приводят к изменению структуры органа, вызывая повышение портального давления и развитие синдрома портальной гипертензии, сопровождающегося и другими нарушениями портального кровотока. Сочетанное течение НАЖБП с гипертонической болезнью (ГБ), безусловно, вызывает повышение тяжести течения как ГБ, скорость ее прогрессирования и повреждение органов-мишеней при ней, так и НАЖБП, вызывая ускорение темпов формирования фибротических изменений в печеночной ткани [1].

В ранее проведенных исследования показано, что при ГБ развиваются тяжелые нарушения со стороны сердечно-сосудистой системы в виде ремоделирования сосудистой стенки, что представляет собой компенсаторно-приспособительную реакцию на повышение артериального давления (АД) и сопровождается гипертрофией мышечной стенки сосудов, накоплению эластических волокон с гиалинозом, повышению ригидности стенки сосуда и уменьшению его просвета [2].

Поражение стенок крупных сосудов при ГБ сопровождается развитием схожих изменений в сосудах меньшего диаметра, что приводит к росту периферического сосудистого сопротивления, обеднению капиллярного русла, локальному спазму артериол и венул и снижению скорости кровотока в обменных сосудах микроциркуляторного русла [3].

Перечень органов-мишеней и патологические процессы в них при ГБ подробно изучены, в отношении изменений в миокарде, почках, головном мозге и других органов [4], однако вопросам поражения печени и, в частности, ее сосудистого русла при ГБ уделено значительно меньшее внимание. Изменение показателей портального кровотока у больных ГБ, безусловно, имеет место, так как сосуды печени повреждаются аналогично сосудам другой локализации. Очевидно, что, с одной стороны, нарушение микроциркуляции в печеночной паренхиме снижает функциональную активность печени, a, с другой стороны, наличие НАЖБП с сопутствующими ей метаболическими нарушениями в значительной степени усиливает повреждение органов-мишеней при ГБ и ухудшает прогноз.

Ранее в исследованиях было показано, что риск развития ишемической болезни сердца (ИБС) у пациентов с НАЖБП в значительной степени превышает таковой в среднем в популяции. Так, в исследовании Chen J. и соавторов были проанализированы клинические исходы у пациентов, перенесших коронарную ангиографию. Из 612 пациентов, включенных в исследование, у 58,2 \% выявили ультрасонографические признаки НАЖБП, у 52,0 \% было зафиксировано повышение уровня АЛТ, а у 76,0 \% пациентов верифицировали диагноз ИБС. В результате статистического анализа данных исследования было обнаружено, что 84,6 \% пациентов с НАЖБП верифицировался диагноз ИБС, а у пациентов, не имеющих патологии печени, ИБС выявлялась только в $64,1 \%$ случаев $(\mathrm{p}<0,001)$, что позволило авторам исследования предположить возможность рассмотрения НАЖБП как одного из ведущих факторов риска развития ИБС $[5,6]$.

В других работах был изучен уровень сывороточных маркеров повреждения печени у пациентов с ИБС на протяжении 3 лет наблюдения. Было выявлено, что уровень сывороточных маркеров повреждения печени у пациентов с сочетанным течением НАЖБП и ИБС был достоверно (у мужчин 
$\mathrm{p}<0,1 ;$ у женщин $\mathrm{p}<0,05)$ выше, чем у лиц $\mathrm{c}$ изолированной ИБС. По мнению авторов исследования, выявленные зависимости отражают провоспалительный статус у пациентов с НАЖБП, что создает дополнительные условия для возникновения и прогрессирования атеросклеротических процессов в коронарных артериях у пациентов с ИБС [7]. Аналогичные результаты были получены в другом исследовании, в котором было показано, что повышение уровня АЛТ в сыворотке крови у больных НАЖБП достоверно повышает риск развития у них в 10-летней перспективе ИБС в сравнении с группой контроля [8].

Исходя из анализа материалов публикаций последних лет, можно сделать вывод о взаимном потенцировании тяжести течения НАЖБП, ГБ и ИБС и наличии у них общих звеньев патогенеза. В имеющихся публикациях по сочетанному течению НАЖБП, ГБ и ИБС не упоминается о возможном влиянии кардиоваскулярной патологии на состояние портального кровотока у пациентов с НАЖБП. В литературе имеются немногочисленные данные о состоянии портального и печеночного кровотока у пациентов с ГБ, а состояние этих гемодинамических показателей у пациентов с ИБС практически не освещается, что указывает на актуальность и новизну указанного направления исследования.

\section{2. Постановка проблемы}

В связи с вышесказанным вызывает определенный научный интерес разработка методов медикаментозной коррекции нарушений портального кровотока у пациентов с НАЖБП в сочетании с кардиоваскулярной патологией. Целью настоящей работы явилось изучение влияния комплексной терапии на протяжении 12 месяцев, которая включала базисную терапию НАЖБП, иАПФ и $\beta$-адреноблокатор, на состояние портального кровотока у пациентов с НАЖБП в сочетании с ГБ и ИБС.

\section{3. Литературный обзор}

В настоящий момент не существует какойлибо общепринятой и утвержденной терапии НАЖБП. Современное лечение этого заболевания определяется наличием ассоциированных с НАЖБП факторов риска у конкретного пациента. Поэтому считается, что общей целью лечения таких пациентов должно быть улучшение качества жизни и, в перспективе, снижение сердечно-сосудистой и печеночной заболеваемости и смертности.

В предыдущих публикациях было показано, что у больных НАЖБП наблюдаются существенные изменения портальной и внутрипеченочной гемодинанамики, зависящие от наличия сопутствующей кардиоваскулярной патологии. У больных НАЖБП наблюдаются структурно-функциональные изменения печени с увеличением ее размера, тенденциями к увеличению диаметра воротной вены, снижению объемных и линейных скоростей кровотока в воротной и селезеночной вене на фоне повышения индекса резистентности и снижения сплено-портального индекса, что представляет собой универсальный механизм ремоделирования печени как органа-мишени при НАЖБП и ее сосудистого русла. По мере присоединения к НАЖБП ГБ и, в особенности, сочетания ГБ и ИБС указанные выше изменения усугубляются [9].

Кроме использования компонентов базисной терапии НАЖБП (гепатопротекторы, урсодезоксихолиевая кислота, статины, сахароснижающие препараты и др.), назначение которых является патогенетически обоснованным и препятствует развитию и прогрессированию ИР, особый интерес представляет назначение препаратов, влияющих на фибротические процессы в печеночной паренхиме, к которым относится, в том числе, такой класс препаратов, как ингибиторы ангиотензин-превращающего фермента (иАПФ). Наряду с основным гипотензивным действием, иАПФ, несмотря на сформировавшееся мнение о их метаболической нейтральности, обладают рядом важных эффектов, которые способны положительным образом влиять на имеющиеся нарушения у больных с ИР, а именно усиливать синтез липопротеидов высокой плотности (ЛПВП), угнетать синтез триглицеридов (ТГ), повышать чувствительность тканей к действию инсулина и усиливать эндогенный фибринолиз [10].

В работах многих исследователей было показано, что у больных с хронической патологией печени происходит активация ренин-ангиотензиновой системы (РАC), которая играет важную роль в развитии фиброза печени. Установлено, что ангиотензин II стимулирует сокращаемость и пролиферацию активированных звездчатых клеток печени и повышает концентрацию трансформирующего фактора роста - $\beta$ [11].

Экспериментальные исследования продемонстрировали, что клиническое применение иАПФ замедляет прогрессирование фиброза печени. В работах $\mathrm{Li} \mathrm{X}$. и соавторов было изучено влияние монотерапии иАПФ на течение цирроза печени. Было выявлено как улучшение морфологической картины, так и снижение уровня трансформирующего фактора роста (ТФР- $\beta$ ) и других маркеров фиброза печеночной паренхимы [12].

В случаях, когда у пациентов с НАЖБП есть сопутствующая патология в виде ГБ, преимущество при выборе тактики лечения следует отдавать среди иАПФ лизиноприлу, который выводится из организма почками, а среди блокаторов ангиотензинпревращающего фермента II - телмисартану единственному препарату этой группы, который может действовать как частичный антагонист PPAR - $\gamma$ [13]. Учитывая эти и ряд других факторов, ингибиторы РАC, которые широко используются в клинической практике и обладают небольшим количеством побочных эффектов, могут рассматриваться в качестве потенциально новой терапевтической стратегии в предупреждении прогрессирования хронических заболеваний печени, особенно в случаях НАЖБП, когда наиболее часто выявляется сочетание основного заболевания с ГБ, ИБС, дислипидемией, сердечной недостаточностью и т. д. 
В последние годы в терапевтической практике все большее внимание исследователей привлекает неселективный $\beta$-адреноблокатор с $\alpha 1$-антагонистическими свойствами - карведилол. К эффектам блокады карведилолом $\alpha 1$-адренорецепторов, расположенных в различных органах и тканях, относятся дилятация вен и артерий, бронхо-дилятация, торможение агрегации тромбоцитов, стимуляция секреции инсулина в поджелудочной железе, снижение уровня ТГ и липопротеидов низкой плотности (ЛПНП), расслабление гладкой мускулатуры мочевого пузыря и др. Адренергическая регуляция тонуса легочных сосудов также осуществляется исключительно с помощью стимуляции $\alpha 1$-адренорецепторов, что не исключает возможного влияния карведилола на уровень давления в легочном стволе [14]. С другой стороны, есть сообщения о высокой эффективности карведилола в отношении снижения внутрипеченочного сосудистого сопротивления, что особо актуально в аспекте наличия портальной гипертензии у больных с хроническими заболеваниями печени [15].

По данным метаанализа 11 больших исследований, неселективные $\beta$-адреноблокаторы, которые давно используются в терапии портальной гипертензии, позволяют значительно снизить риск первого кровотечения приблизительно на 30-40\%. Эти препараты снижают портальный, коллатеральный и спланхнический кровоток и уменьшают объем сердечного выброса. Назначение препаратов этой группы можно считать эффективным, при условии использования адекватных доз, а именно таких, которые обеспечивают снижение частоты пульса в покое на $25 \%$ или до 55 ударов в минуту при изначально низкой частоте пульса. Рекомендован длительный прием этих препаратов пациентами с наличием синдром портальной гипертензии [16].

Существуют единичные сообщения о положительном влиянии на показатели портальной гемодинамики и предупреждение развития кровотечений из варикозно-расширенных вен пищевода и желудка на фоне применения лизиноприла у пациентов с синдромом портальной гипертензии с одновременной нормализацией клинико-лабораторных показателей. Наряду с этим, в исследовании М. А. Визе-Хрипуновой и соавторов лизиноприл достоверно снижал уровень давления в системе воротной вены и легочной артерии, а также влиял на процесс обратного ремоделирования миокарда, в связи с чем он может быть использован как препарат выбора для коррекции синдрома портальной гипертензии [17].

Работ, посвященных оценке влияния карведилола и лизиноприла на основные показатели портального и внутрипеченочного кровотока при НАЖБП и ее сочетании с ГБ и ИБС, не найдено.

Разнообразие факторов риска, сложность патогенеза и олигосимптомность НАЖБП создают сложности при выборе фармакотерапии названной категории пациентов. Медикаментозное вмешательство при этом сопряжено с возможностью непредсказуемых взаимодействий лекарственных препаратов с активными ферментами поврежденной печеночной ткани. Таким образом, при выборе метода коррекции нарушений портального кровотока и внутрипеченочной гемодинамики у пациентов с НАЖБП необходим дифференцированный подход в выборе медикаментозных препаратов в зависимости от наличия факторов риска, степени тяжести заболевания, особенностей его течения, выраженности нарушений гемодинамики бассейна воротной вены и наличия сопутствующей кардиоваскулярной патологии, что делает тему исследования актуальной и своевременной.

Исследование выполнено в рамках научноисследовательских работ отдела заболеваний печени и желудочно-кишечного тракта ГУ «Национальный институт терапии им. Л. Т. Малой НАМН Украины» «Определить методы диагностики прогрессирования неалкогольной жировой болезни печени у больных с метаболическим синдромом с учетом гематологических маркеров фиброза» (№ государственной регистрации 0106U012449) и «Разработать способы выявления и профилактики неалкогольной жировой болезни печени на основании изучения клинических, фено- и генотипических особенностей у пациентов с метаболическим синдромом» (№ государственной регистрации 0110U002879).

\section{4. Материалы и методы исследования}

В группу исследуемых было включено 140 пациентов (86 мужчин и 54 женщины) в возрасте от 20 до 74 лет, причем большая часть пациентов попадала в возрастной интервал 41-60 лет, а средний возраст составил 46,5 $\pm 8,5$ лет, с диагнозом НАЖБП (n=40), с НАЖБП в сочетании с ГБ $(\mathrm{n}=54)$ и с НАЖБП в сочетании с ГБ и ИБС $(\mathrm{n}=46)$. Диагноз НАЖБП выставлялся на основании клинических, биохимических и сонографических маркеров. Длительность течения НАЖБП у исследуемого контингента колебалась в пределах от 2 до 12 лет и в среднем составляла в группе НАЖБП - 2,7 $\pm 1,8$ лет, в группе НАЖБП в сочетании с ГБ $-3,8 \pm 2,2$ года и в группе НАЖБП в сочетании с ГБ и ИБС $-6,4 \pm 2,6$ года.

Критериями исключения для включения пациентов в исследование было наличие признаков неалкогольного стеатогепатита 3 степени, выраженного фиброза печеночной паренхимы, цирроза печени и портальной гипертензии по данным УЗИ, вирусных гепатитов любой этиологии, воспалительных поражений печени токсической этиологии на момент включения в исследование или в анамнезе. Кроме того, в исследование не включались пациенты с протезированием клапанов сердца в анамнезе и гемодинамически значимыми повреждениями клапанов сердца, хроническими обструктивными заболеваниями легких, гипертонической болезнью 3 степени, с признаками выраженной острой и хронической сердечной недостаточности.

Bce пациенты, включенные в исследование, методом простой рандомизации были разделены на 3 группы: группа 1-40 пациентов с изолированной НАЖБП (получали базисную терапию НАЖБП), группа 2-54 пациента с НАЖБП в сочетании с ГБ 
(получали базисную терапию НАЖБП+иАПФ), группа 3 - 46 пациентов с НАЖБП в сочетании с ГБ и ИБС (получали базисную терапию НАЖБП+ +иАПФ+неселективный $\beta$-адреноблокатор).

В состав базисной терапии НАЖБП, которую получали пациенты всех групп были включены урсодезоксихолиевая кислота по 750 мг в сутки и метформин по 2000 мг в сутки. Пациенты 2 группы дополнительно к базисной терапии НАЖБП получали иАПФ лизиноприл в начальной дозировке 2,5 мг в сутки с последующим титрованием дозы, а пациенты 3 группы - комбинацию лизиноприла в указанной выше дозировке с неселективным $\beta$-адреноблокатором карведилолом 3,125 мг 2 раза в сутки с последующим титрованием дозы.

В исследуемых группах оценивали состояние портального кровотока по данным эхосонографического исследования в динамике проводимой комплексной терапии на протяжении 12 месяцев с контрольными исследованиями оцениваемых показателей через 1, 6 и 12 месяцев с момента начала терапии.

Рандомизированные группы сравнения были сопоставимы по полу, возрасту, длительности течения НАЖБП и степени ее активности.

Верификацию диагноза НАЖБП проводили на основании результатов эхосонографического сканирования паренхимы печени, в ходе которого оценивали размеры и контуры печени, состояние нижнего края правой доли печени, эхоструктуру и сосудистую архитектонику печеночной паренхимы. Наличие стеатогепатита различной степени выраженности у пациентов с НАЖБП косвенно оценивали по наличию биохимических сывороточных маркеров воспалительного повреждения печеночной парехнимы (повышение уровней АЛТ, АСТ и гаммаглутамилтранспептидазы (ГГТП)).

Эхосонографическое обследование проводили натощак с использованием ультразвукового сканера экспертного класса «Philips IU22» (США) конвексным мультичастотным датчиком с диапазоном частот 2-5 МГц. В ходе исследования у каждого пациента определяли размеры долей печени, оценивали структуру печеночной паренхимы, архитектонику внутрипеченочных сосудов и сосудов бассейна воротной вены (BВ), состояние элементов желчевыводящей системы, размеры и строение селезенки. Оценивали диаметр общей печеночной артерии, внутрипеченочного отдела ВB, диаметр селезеночной вены $(\mathrm{CB})$ в воротах селезенки. В анализ были также включены показатели, прямо и косвенно характеризующие состояние портального кровотока у исследуемых пациентов, а именно диаметры общей печеночной артерии, внутрипеченочного отдела ВВ и СВ в воротах селезенки. Для каждого из названных выше сосудов определяли линейные и объемные скорости кровотока, а именно линейную скорость кровотока в воротной вене
(ЛСКВВ), объемную скорость кровотока в воротной вене (ОСКВВ), линейную скорость кровотока в селезеночной вене (ЛСКСВ), объемную скорость кровотока в селезеночной вене (ОСКСВ) и объемную скорость кровотока в общей печеночной артерии (ОСКОПА).

На основании указанных выше допплерографических показателей портального кровотока рассчитывали индекс резистентности (RI, отношение разницы между максимальной систолической и конечной диастолической скоростью к максимальной систолической скорости кровотока) и спленопортальный индекс (СПИ, отношение ОСКСВ к ОСКВВ, \%). Дополнительно рассчитывали и оценивали индекс гиперемии, общий печеночный объемный кровоток, индекс артериальной перфузии и печеночный сосудистый индекс.

Верификацию диагноза ИБС проводили по стандартной схеме с использованием данных анамнеза, оценки клинической картины и данных инструментальных исследований, которые включали коронарографию, тредмил-тест и велоэргометрию, с последующим указанием функционального класса (ФК) ИБС по классификации Канадской ассоциации кардиологов.

Верификацию диагноза ГБ проводили на основании данных анамнеза, клинического обследования пациентов, наличия характерных поражений органов-мишеней и данных инструментального мониторинга АД. Измерение уровня АД проводили с оценкой как систолического, так и диастолического АД по методу Н.С. Короткова в положении больного сидя и лежа после 15-минутного покоя с использованием сфигноманометра Erka, Chemnitz, Германия.

Статистическая оценка полученных в ходе исследования данных проводилась с помощью стандартных методов вариационной статистики. Для обработки полученных данных использовала пакет статистических программ «STATISTIKA - 6.0». Достоверность отличий между сравниваемыми показателями в случае нормального распределения изучаемого признака определяли с помощью критерия Стьюдента (t-критерия) для зависимых и независимых выборок, а при распределении изучаемого признака, отличного от нормального, - с помощью непараметрических критериев МаннаУитни и Уилкоксона. Достоверными считали отличия между сравниваемыми показателями при значениях $\mathrm{p}<0,05$.

\section{5. Результаты исследования}

Данные изменений эхосонографических показателей стуктурно-функционального состояния печени и показателей портального кровотока в динамике проведения комплексной терапии приведены в табл. 1. 
Таблица 1

Динамика изменения основных параметров состояния печени, портального и внутрипеченочного кровотока в динамике лечения

\begin{tabular}{|c|c|c|c|c|c|c|}
\hline \multirow{2}{*}{ Показатель } & \multicolumn{2}{|c|}{$\begin{array}{l}\text { Больные НАЖБП } \\
\text { (1 гр.), n=40 }\end{array}$} & \multicolumn{2}{|c|}{$\begin{array}{c}\text { Больные НАЖБП+ГБ } \\
(2 \text { гр.), } \mathrm{n}=54\end{array}$} & \multicolumn{2}{|c|}{$\begin{array}{c}\text { Больные НАЖБП+ГБ+ИБС } \\
\text { (3 гр.), } n=46\end{array}$} \\
\hline & До лечения & $\begin{array}{c}\text { После } \\
\text { лечения }\end{array}$ & До лечения & $\begin{array}{c}\text { После } \\
\text { лечения }\end{array}$ & До лечения & После лечения \\
\hline Правая доля, мм & $\begin{array}{c}144,7 \\
(120,23 ; 152,33)\end{array}$ & $\begin{array}{c}120,3 \\
(116,7 ; 128,8) \\
\mathrm{p}_{1}=0,001 \\
\end{array}$ & $\begin{array}{c}148,3 \\
(140,23 ; 155,98)\end{array}$ & $\begin{array}{c}140,2 \\
(132,6 ; 152,9) \\
\mathrm{p}_{2}=0,001 \\
\end{array}$ & \begin{tabular}{c|}
158,55 \\
$(145,68 ; 169,43)$
\end{tabular} & $\begin{array}{c}148,6 \\
(140,3 ; 152,4) \\
\mathrm{p}_{3}=0,001 \\
\end{array}$ \\
\hline Левая доля, мм & $\begin{array}{c}77,5 \\
(72,15 ; 79,58)\end{array}$ & $\begin{array}{c}72,6 \\
(70,3 ; 74,8) \\
\mathrm{p}_{1}=0,001 \\
\end{array}$ & $\begin{array}{c}78 \\
(69,98 ; 90,4)\end{array}$ & $\begin{array}{c}75,8 \\
(74,3: 76,9) \\
\mathrm{p}_{2}=0,001\end{array}$ & $\begin{array}{c}85,2 \\
(81,13 ; 87,7)\end{array}$ & $\begin{array}{c}78,9 \\
(76,5 ; 81,4) \\
\mathrm{p}_{3}=0,001\end{array}$ \\
\hline $\begin{array}{ll}\text { Диаметр } & \text { воротной } \\
\text { вены, мм } & \end{array}$ & $\begin{array}{c}9,65 \\
(9,33 ; 10,43)\end{array}$ & $\begin{array}{c}9,55 \\
(9,28 ; 9,9) \\
\mathrm{p}_{1}=0,001 \\
\end{array}$ & $\begin{array}{c}9,95 \\
(9,5 ; 10,85)\end{array}$ & $\begin{array}{c}9,6(9,4 ; 9,8) \\
\mathrm{p}=0,01\end{array}$ & $\begin{array}{c}10,2 \\
(9,6 ; 11,03)\end{array}$ & $\begin{array}{c}9,75 \\
(9,2 ; 10,8) \\
\mathrm{p}_{3}=0,001\end{array}$ \\
\hline $\begin{array}{l}\text { Линейная } \\
\text { кровотока в в } \\
\text { ворость } \\
\text { вене, ЛСКВВ, см/c }\end{array}$ & $\begin{array}{c}15 \\
(12,68 ; 16,38)\end{array}$ & $\begin{array}{c}14,8 \\
(12,8 ; 15,9) \\
\mathrm{p}=0,01\end{array}$ & $\begin{array}{c}14,2 \\
(11,23 ; 15,88)\end{array}$ & $\begin{array}{c}14,8 \\
(12,6 ; 17,0) \\
\mathrm{p}_{2}=0,001\end{array}$ & $\begin{array}{c}11,65 \\
(9,73 ; 15,2)\end{array}$ & $\begin{array}{c}13,2 \\
(10,6 ; 14,7) \\
\mathrm{p}_{3}=0,001\end{array}$ \\
\hline $\begin{array}{l}\text { Объемная } \\
\text { кровотока в в } \\
\text { ворость } \\
\text { вене, ОСКВВ, мл/мин. }\end{array}$ & $\begin{array}{c}662,8 \\
(617,3 ; 702,93)\end{array}$ & $\begin{array}{c}660,5 \\
(638,9 ; 680,7) \\
\mathrm{p}_{1}=0,001\end{array}$ & $\begin{array}{c}685,2 \\
(598,03 ; 713,65)\end{array}$ & $\begin{array}{c}672,5 \\
(658,6 ; 684,5) \\
\mathrm{p}_{2}=0,001\end{array}$ & $\begin{array}{c}701,25 \\
(603,9 ; 791,05)\end{array}$ & $\begin{array}{c}680,5 \\
(640,6 ; 698,4) \\
\mathrm{p}_{3}=0,001\end{array}$ \\
\hline $\begin{array}{l}\text { Размеры селезенки, } \\
\text { см}^{2}\end{array}$ & $\begin{array}{c}27,3 \\
(25,43 ; 29,2)\end{array}$ & $\begin{array}{c}27,0 \\
(26,5 ; 27,8) \\
\mathrm{p}_{1}=0,001\end{array}$ & $\begin{array}{c}28,8 \\
(23,2 ; 30,1)\end{array}$ & $\begin{array}{c}27,5 \\
(26,8 ; 28,4) \\
\mathrm{p}_{2}=0,001\end{array}$ & $\begin{array}{c}28,2 \\
(24,73 ; 32,98)\end{array}$ & $\begin{array}{c}27,9 \\
(28,2 ; 29,3) \\
\mathrm{p}_{3}=0,001\end{array}$ \\
\hline 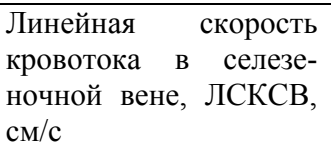 & $\begin{array}{c}20,99 \\
(18,63 ; 22,36)\end{array}$ & $\begin{array}{c}20,1 \\
(19,2 ; 28,6) \\
\mathrm{p}_{1}=0,001\end{array}$ & $\begin{array}{c}18,60 \\
(17,63 ; 20,47)\end{array}$ & $\begin{array}{c}19,8 \\
(18,4 ; 21,0) \\
\mathrm{p} 2=0,001\end{array}$ & $\begin{array}{c}16,57 \\
(15,48 ; 19,57)\end{array}$ & $\begin{array}{c}18,8 \\
(16,9 ; 20,6) \\
p_{3}=0,001\end{array}$ \\
\hline $\begin{array}{l}\text { Объемная } \\
\text { кровотока в ворость } \\
\text { ночной вене, ОСКСВ, } \\
\text { мл/мин. }\end{array}$ & $\begin{array}{c}310,12 \\
(297,41 ; 314,29)\end{array}$ & $\begin{array}{c}310,15 \\
(298,4 ; 312,6) \\
\mathrm{p}_{1}=0,001\end{array}$ & $\begin{array}{c}295,79 \\
(264,3 ; 312,45)\end{array}$ & $\begin{array}{c}300,65 \\
(287,8 ; 306,7) \\
\mathrm{p}_{2}=0,001\end{array}$ & $\begin{array}{c}236,22 \\
(213,89 ; 251,59)\end{array}$ & $\begin{array}{c}266,9 \\
(248,5 ; 270,6) \\
\mathrm{p}_{3}=0,001\end{array}$ \\
\hline $\begin{array}{l}\text { RI (индекс резис- } \\
\text { тентности) }\end{array}$ & $\begin{array}{c}0,64 \\
(0,58 ; 0,71)\end{array}$ & $\begin{array}{c}0,63 \\
(0,56 ; 0,68) \\
\mathrm{p}_{1}=0,001\end{array}$ & $\begin{array}{c}0,65 \\
(0,62 ; 0,69)\end{array}$ & $\begin{array}{c}0,64 \\
(0,60 ; 0,66) \\
\mathrm{p}_{2}=0,001\end{array}$ & $0,68(0,61 ; 0,74)$ & $\begin{array}{c}0,65 \\
(0,61 ; 0,68) \\
\mathrm{p}_{3}=0,001\end{array}$ \\
\hline $\begin{array}{l}\text { СПИ, \% (сплено-пор- } \\
\text { тальный индекс) }\end{array}$ & $\begin{array}{c}42,83 \\
(40,37 ; 45,74)\end{array}$ & $\begin{array}{c}44,2 \\
(40,8 ; 46,9) \\
\mathrm{p}_{1}=0,001 \\
\end{array}$ & $\begin{array}{c}41,3 \\
(39,70 ; 42,89)\end{array}$ & $\begin{array}{c}43,4 \\
(40,2 ; 45,6) \\
\mathrm{p}_{2}=0,001 \\
\end{array}$ & $\begin{array}{c}39,35 \\
(35,71 ; 40,95)\end{array}$ & $\begin{array}{c}42,6 \\
(40,4 ; 45,8) \\
\mathrm{p}_{3}=0,001 \\
\end{array}$ \\
\hline
\end{tabular}

Примечания: $p_{1}-$ значимость отличий показателей до и после лечения для 1 группь; $p_{2}-$ значимость отличий показателей до и после лечения для 2 группь; $p_{3}$ - значимость отличий показателей до и после лечения для 3 группь.

На фоне проведенной комплексной терапии во всех выделенных группах больных наблюдалось достоверное улучшение эхосонографических показателей печени. Так, у больных НАЖБП наблюдалось достоверное уменьшение размеров правой доли печени, а именно у лиц 1 группы до $120,3(116,7 ; 128,8)$ см, $p_{1}=0,001$, у лиц 2 группы - до $140,2(132,6 ; 152,9) \mathrm{cm}, \mathrm{p}_{2}=0,001$, у лиц 3 группы - до $148,6(140,3 ; 152,4) \mathrm{cm}, \mathrm{p}_{3}=0,001$.

Соответствующие изменения были характерны и для левой доли печени. Так, наблюдалось достоверное уменьшение размеров левой доли печени у лиц 1 группы $\left(72,6(70,3 ; 74,8) \mathrm{cm}, \mathrm{p}_{1}=0,001\right)$, а также у лиц $2\left(75,8(74,3: 76,9) \mathrm{cm}, \mathrm{p}_{2}=0,001\right)$ и $3\left(78,9(76,5 ; 81,4) \mathrm{cм}, \mathrm{p}_{3}=0,001\right)$ групп.

Для всех больных было характерно уменьшение диаметра $\mathrm{BB}$ на фоне проводимой комплексной терапии, но у пациентов 2 группы эти изменения были недостоверны. Уменьшение диаметра ВB у пациентов 3 группы достигало значений $9,75(9,2 ; 10,8) \mathrm{MM}, \mathrm{p}_{3}=0,001$, а у лиц 1 группы - 9,55 $(9,28 ; 9,9)$ мм, $\mathrm{p}_{1}=0,001$.
При анализе ЛСКВВ на фоне проведенного лечения наблюдалось достоверное ее повышение у больных НАЖБП в сочетании с кардиальной патологией. У пациентов 2 группы показатели ЛСКВВ составили после лечения $14,8(12,6 ; 17,0) \mathrm{cm} / \mathrm{c}$, $\mathrm{p}_{2}=0,001$, а у больных 3 группы - 13,2 (10,6; $14,7) \mathrm{cm} / \mathrm{c}, \mathrm{p}_{3}=0,001$. Изменение ЛСКВВ у пациентов 1 группы были недостоверны.

Во всех выделенных группах на фоне лечения была выявлена четкая тенденция к нормализации ОСКВВ. Выявленная динамика была достоверной для пациентов всех групп сравнения. Так, у лиц 1 группы показатели ОСКВВ составили 660,5 (638,9; $680,7)$ мл/мин., $p_{1}=0,001,2$ группы - 672,5 (658,6; $684,5)$ мл/мин., $\mathrm{p}_{2}=0,001$, а в 3 группе $-680,5(640,6$; $698,4)$ мл/мин., $\mathrm{p}_{3}=0,001$.

Также во всех выделенных группах пациентов с НАЖБП наблюдалось достоверное уменьшение размеров селезенки, выраженное в большей степени в группах пациентов с сопутствующей кардиоваскулярной патологией: у пациентов 2 группы размеры селезенки уменьшились до 27,5 (26,8; 
28,4) см, $\mathrm{p}_{2}=0,001$, а у пациентов 3 группы - до $27,9(28,2 ; 29,3) \mathrm{cm}, \mathrm{p}_{3}=0,001$.

При анализе показателей кровотока в селезеночной вене было выявлено достоверное повышение как показателей линейного, так и показателей объемного кровотока. Так, для пациентов с НАЖБП в сочетании с ГБ и ИБС было характерно значимое достоверное повышение ЛСКСВ и ОСКСВ до $18,8(16,9 ; 20,6)$ мл/мин. и 266,9 $(248,5 ; 270,6)$ мл/мин., $\mathrm{p}_{3}=0,001$ соответственно. У пациентов с НАЖБП в сочетании с ГБ ЛСКСВ и ОСКСВ на фоне проведенной терапии достигли значений $19,8 \quad(18,4 ; 21,0)$ мл/мин. и 300,65 $(287,8 ; 306,7)$ мл/мин., $\mathrm{p}_{2}=0,001$, соответственно.

При оценке индекса резистентности во всех группах пациентов было зафиксировано достоверное уменьшение его числовых значений, в наибольшей степени выраженное у пациентов 3 группы со значения до лечения, равного $0,68(0,61 ; 0,74)$, до значения после лечения, равного $0,65(0,61 ; 0,68)$, $\mathrm{p}_{3}=0,001$. Достоверным, однако менее выраженным, было снижение индекса резистентности у пациентов 1 и 2 групп до значений $0,63(0,56 ; 0,68), \mathrm{p}_{1}=0,001$, и $0,64(0,60 ; 0,66), \mathrm{p}_{2}=0,001$, соответственно.

Значения СПИ также демонстрировали достоверные тенденции к нормализации на фоне проводимой комплексной терапии, повышаясь во всех группах: в группе 1 - до значений 44,2 \% $(40,8 ; 46,9), \mathrm{p}_{1}=0,001$, в группе 2 - до значений $43,4 \%$ $(40,2 ; 45,6), \mathrm{p}_{2}=0,001$, а у пациентов 3 группы - до $42,6 \%(40,4 ; 45,8), \mathrm{p}_{3}=0,001$.

\section{6. Выводы}

Таким образом, наиболее значимые изменения печени как органа-мишени при НАЖБП наступают у пациентов при ассоциации последней с ГБ и ИБС. Больные НАЖБП в сочетании с сердечно-сосудистой патологией представляют собой группы потенциального риска формирования выраженного фиброза печеночной паренхимы, сопровождающегося определенными изменениями портального кровотока, что свидетельствует о формировании доклинической портальной гипертензии. Наиболее информативными для диагностики доклинической портальной гипертензии у пациентов с НАЖБП можно считать индекс резистентности и СПИ, отображающие повышение жесткости сосудистой стенки, которая первой реагирует на изменения эластичности печеночной паренхимы.

Анализируя приведенные выше данные можно утверждать, что достоверные уменьшение диаметра воротной вены и нормализация показателей портосистемного шунтирования в паренхиме печени в сочетании с ростом линейных и объемных скоростей кровотока в селезеночной и воротной венах на фоне снижения индекса резистентности и повышения СПИ у пациентов с НАЖБП в сочетании с кардиоваскулярной патологией на фоне предложенной комплексной терапии были признаками снижения давления в системе воротной вены и способствовали профилактике формирования у исследуемого контингента лиц портопульмонального синдрома.
Изучение динамики основных исследуемых показателей состояния портального кровотока продемонстрировало, что в группе пациентов с НАЖБП в сочетании с ГБ в результате проведенной комплексной терапии отмечаются положительные гемодинамические изменения, которые носят системный, корреляционно взаимозависимый и взаимосвязанных характер, что доказывает преимущественно вазодилятационное действие лизиноприла и его высокую эффективность в отношении, в том числе, сосудов бассейна воротной вены. В еще большей степени выраженные аналогичные изменения показателей портального кровотока определялись в группе пациентов с НАЖБП в сочетании с ГБ и ИБС, что, вероятно, объясняется взаимопотенцирующим действием лизиноприла и карведилола в отношении их влияния на состояние сосудистой стенки и сосудистое сопротивление в бассейне воротной вены на фоне нормализации показателей портального кровотока и снижения системного артериального давления, что в значительной степени позволяет профилактировать развитие не только портальной гипертензии, но предотвращает прогрессирование фибротических изменений в паренхиме печени и самой НАЖБП.

В итоге, на основании проведенного исследования больным с НАЖБП в сочетании с ГБ можно рекомендовать добавление к базисной терапии НАЖБП лизиноприла в суточной дозировке 2,5 мг с последующим титрованием дозы, а при сочетании НАЖБП с ГБ и ИБС - комбинации лизиноприла в суточной дозировке 2,5 мг с карведилолом по 3,125 мг 2 раза в сутки с последующим титрованием дозы обоих препаратов для достижения максимальной эффективности проводимой терапии.

\section{Литература}

1. Сторожаков, Г. И. Патогенетические аспекты фиброгенеза при хронических заболеваниях печени [Текст] / Г. И. Сторожаков, А. Н. Ивкова // Клинические перспективы в гастроэнтерологии, гепатологии. - 2009. - № 2. - С. 3-10.

2. Агафонов, А. В. Артериальное ремоделирование у больных артериальной гипертензией пожилого и старшего возраста [Текст] / А. В. Агафонов, А. В. Туев, Л. А. Некрутенко, Ю. В. Бочкова // Российский кардиологический журнал. - 2005. №3. - C. 25-28.

3. Versari, D. Endothelium-dependent contractions and endothelial dysfunction in human hypertension [Text] / D. Versari, E. Daghini, A. Virdis et al. // British Journal of Pharmacology. - 2009. Vol. 157, Issue 4. - P. 527-536. doi: 10.1111/j.14765381.2009.00240.x

4. Oparil, S. Pathogenesis of arterial hypertension [Text] / S. Oparil, A. Zaman, D. A. Calhoun // Annals of Internal Medicine. - 2003. - № 139. - P. 7617-7626.

5. Chen, J. Early detection of nonalcoholic steatohepatitis in patients with nonalcoholic fatty liver disease by using $\mathrm{mr}$ elastography [Text] / J. Chen, J. A. Talwalkar, M. Yin, K. J. Glaser, S. O. Sanderson, 
R. L. Ehman // Radiology. - 2011. - Vol. 259, Issue 3. P. 749-756. doi: 10.1148/radiol.11101942

6. Wong, V.W. Prevalence of non-alcoholic fatty liver disease and advanced fibrosis in Hong Kong Chinese: a population study using proton-magnetic resonance spectroscopy and transient elastography [Text] / V.W. Wong, W.C. Chu G. L.-H. Wong, R. S.-M. Chan, A. M.-L. Chim, A. Ong, D. K.-W. Yeung, K. K.-L. Yiu, S. H.-T. Chu, J. Woo, F. K.-L. Chan, H. L.-Y. Chan // Gut. - 2011. - Vol. 61, Issue 3. - P. 409-415. doi: 10.1136/gutjnl-2011-300342

7. Thiruvagounder, $M$. The prevalence of metabolic syndrome in India [Text] / M. Thiruvagounder, S. Khan, D. S. Sheriff // Biochemia Medica. - 2010. Vol. 20 (2). - P. 249-252.

8. Ioannou, G. N. Elevated serum alanine aminotransferase activity and calculated risk of coronary heart disease in the United States [Text] / G. N. Ioannou, N. S. Weiss, E. J. Boyko, D. Mozaffarian, S. P. Lee // Hepatology. - 2006. - Vol. 43, Issue 5. - P. 1145-1151. doi: $10.1002 /$ hep. 21171

9. Козлов, О. П. Стан портального кровотоку у хворих на неалкогольну жирову хворобу печінки [Текст] / О. П. Козлов // Актуальні проблеми сучасної медицини: Вісник Української медичної стоматологічної академії. - 2012. - Т. 12, Вип. 3 (39). C. $46-50$.

10. Paschos, P. Nonalcoholic fatty liver disease and the renin-angiotensin system: Implications for treatment [Text] / P. Paschos, K. Tziomalos // World J. Hepatol. - 2012. - Vol. 27, Issue 4(12). - P. 327-331.

11. Yoshiji, H. Blockade of renin-angiotensin system in antifibrotic therapy [Text] / H. Yoshiji, S. Kuriyama, H. Fukui // Journal of Gastroenterology and Hepatology. - 2007. - Vol. 22, Issue s1. - P. 893-895. doi: $10.1111 / \mathrm{j} .1440-1746.2006 .04663 . x$

12. Huang, M. L. Upregulation of angiotensinconverting enzyme (ACE) 2 in hepatic fibrosis by ACE inhibitors [Text] / M.L. Huang, X. Li, Y. Meng, B. Xiao, Q. Ma, S.S. Ying, P.S. Wu, Z.S. Zhang // Clinical and Experimental Pharmacology and Physiology. - 2010. Vol. 37, Issue 1. - P. 1-6. doi: 10.1111/j.14401681.2009.05302.x

13. Li, L. Telmisartan improves insulin resistance of skeletal muscle through peroxisome proliferatoractivated receptor- $\delta$ activation [Text] / L. Li, Z. Luo, H. Yu, X. Feng, P. Wang, J. Chen, Y. Pu, Y. Zhao, H. He, J. Zhong, D. Liu, Z. Zhu // Diabetes. - 2013. Vol. 62, Issue 3. - P. 762-774. doi: 10.2337/db12-0570

14. Drake, J. I. Chronic carvedilol treatment partially reverses the right ventricular failure transcriptional profile in experimental pulmonary hypertension [Text] / J. I. Drake, J. Gomez-Arroyo, C. I. Dumur, D. Kraskauskas, R. Natarajan, H. J. Bogaard, P. Fawcett, N. F. Voelkel // Physiological Genomics. - 2013. - Vol. 45, Issue 12. - P. 449-461. doi: 10.1152/physiolgenomics.00166.2012

15. Hobolth, L. Effects of carvedilol and propranolol on circulatory regulation and oxygenation in cirrhosis: a randomised study [Text] / L. Hobolth, F. Bendtsen, E.F. Hansen // Digestive and Liver Disease.
- 2014. - Vol. 46, Issue 3. - P. 251-256. doi: 10.1016/j.dld.2013.10.013

16. Ko, S. Y. Pharmacotherapy alone vs endoscopic variceal ligation combination for secondary prevention of oesophageal variceal bleeding: metaanalysis [Text] / S. Y. Ko, J. H. Kim, W. H. Choe, S. Y. Kwon, C. H. Lee // Liver International. - 2012. Vol. 32, Issue 5. - P. 867-869. doi: 10.1111/j.14783231.2011.02681.x

17. Визе-Хрипунова, М. А. Эффективность лизиноприла в коррекции портальной гипертензии у больных циррозом печени [Текст] / М. А. ВизеХрипунова, Н. С. Загоранская, С. А. Исмаилова // Росс. журнал гастроэнтерологии, гепатологии и колопроктологии. Приложение № 26. - Материалы Одиннадцатой Российской Гастроэнтерологической недели. - Москва, 2005. - С. 69.

\section{References}

1. Storozhakov, G. I., Ivkova, A. N. (2009). Patogeneticheskie aspektyi fibrogeneza pri hronicheskih zabolevaniyah pecheni (Pathogenetic aspects of fibrogenesis in chronic liver diseases). Clinical Perspectives in Gastroenterology, Hepatology, 2, 3-10.

2. Agafonov, A. V., Tuev, A. V., Nekrutenko, L. A., Bochkova, Yu. V. (2005). Arterialnoe remodelirovanie u bolnyih arterialnoy gipertenziey pozhilogo i starshego vozrasta (Arterial remodeling in hypertensive patients of elderly and older). Russian Cardiology Journal, 3, 25-28.

3. Versari, D., Daghini, E., Virdis, A. et al. (2009). Endothelium-dependent contractions and endothelial dysfunction in human hypertension. British Journal of Pharmacology, 157 (4), 527-536. doi: 10.1111/j.14765381.2009.00240.x

4. Oparil, S., Zaman, A., Calhoun, D. A. (2003). Pathogenesis of arterial hypertension. Annals of Internal Medicine, 139, 7617-7626.

5. Chen, J., Talwalkar, J. A., Yin, M., Glaser, K. J., Sanderson, S. O., Ehman, R. L. (2011). Early Detection of Nonalcoholic Steatohepatitis in Patients with Nonalcoholic Fatty Liver Disease by Using MR Elastography. Radiology, 259 (3), 749-756. doi: 10.1148/radiol.11101942

6. V.W. Wong, W.C. Chu G. L.-H. Wong, R. S.M. Chan, A. M.-L. Chim, A. Ong, D. K.-W. Yeung, K. K.-L. Yiu, S. H.-T. Chu, J. Woo, F. K.-L. Chan, H. L.-Y. Chan (2011). Prevalence of non-alcoholic fatty liver disease and advanced fibrosis in Hong Kong Chinese: a population study using proton-magnetic resonance spectroscopy and transient elastography. Gut, 61 (3), 409-415. doi: 10.1136/gutjnl-2011-300342

7. Thiruvagounder, M., Khan, S., Sheriff, D. S. (2010). The prevalence of metabolic syndrome in India. Biochemia Medica, 20 (2), 249-252.

8. Ioannou, G. N., Weiss, N. S., Boyko, E. J., Mozaffarian, D., Lee, S. P. (2006). Elevated serum alanine aminotransferase activity and calculated risk of coronary heart disease in the United States. Hepatology, 43 (5), 1145-1151. doi: 10.1002/hep.21171

9. Kozlov, O. P. (2012). Stan portalnogo krovotoku u hvorih na nealkogolnu zhirovu hvorobu pechInki (Status of portal blood flow in patients with 
nonalcoholic fatty liver disease). Actual problems of modern medicine: Bulletin of the Ukrainian Medical Dental Academy, 12/3 (39), 46-50.

10. Paschos, P., Tziomalos, K. (2012). Nonalcoholic fatty liver disease and the reninangiotensin system: Implications for treatment . World J. Hepatol., 4 (12), 327-331.

11. Yoshiji, H., Kuriyama, S., Fukui, H. (2007). Blockade of renin-angiotensin system in antifibrotic therapy. Journal of Gastroenterology and Hepatology, 22 (s1), 893-895. doi: 10.1111/j.1440-1746.2006.04663.x

12. Huang, M. L., Li, X., Meng, Y., Xiao, B., Ma, Q., Ying, S. S., Wu, P. S., Zhang, Z. S. (2010). Upregulation of angiotensin-converting enzyme (ACE) 2 in hepatic fibrosis by ACE inhibitors. Clinical and Experimental Pharmacology and Physiology, 37 (1). - P. 1-6. doi: 10.1111/j.1440-1681.2009.05302.x

13. Li, L., Luo, Z., Yu, H., Feng, X., Wang, P., Chen, J., Pu, Y., Zhao, Y., He, H., Zhong, J., Liu, D., Zhu, Z. (2013). Telmisartan improves insulin resistance of skeletal muscle through peroxisome proliferatoractivated receptor- $\delta$ activation. Diabetes, 62 (3), 762774. doi: $10.2337 / \mathrm{db} 12-0570$

14. Drake, J. I., Gomez-Arroyo, J., Dumur, C. I., Kraskauskas, D., Natarajan, R., Bogaard, H. J., Faw- cett, P., Voelkel, N. F. (2013). Chronic carvedilol treatment partially reverses the right ventricular failure transcriptional profile in experimental pulmonary hypertension. Physiological Genomics, 45 (12), 449-461. doi: 10.1152/physiolgenomics.00166.2012

15. Hobolth, L., Bendtsen, F., Hansen, E. F. (2014). Effects of carvedilol and propranolol on circulatory regulation and oxygenation in cirrhosis: a randomised study. Digestive and Liver Disease, 46 (3), 251-256. doi: 10.1016/j.dld.2013.10.013

16. Ko, S. Y., Kim, J. H., Choe, W. H., Kwon, S. Y., Lee, C. H. (2012). Pharmacotherapy alone vs endoscopic variceal ligation combination for secondary prevention of oesophageal variceal bleeding: meta-analysis. Liver International, 32 (5), 867-869. doi: 10.1111/j.14783231.2011.02681.x

17. Vize-Hripunova, M. A., Zagoranskaya, N. S., Ismailova, S. A. (2005). Effektivnost lizinoprila v korrektsii portalnoy gipertenzii u bolnyih tsirrozom pecheni (Efficacy of lisinopril in the correction of portal hypertension in patients with liver cirrhosis). Russian Journal of Gastroenterology, Hepatology and Coloproctology, 26, 69 .

Рекомендовано до публікації д-р мед. наук Крахмалова О. О. Дата надходження рукопису 14.11.2014

Козлов Александр Петрович, ассистент, кафедра гигиены и социальной медицины медицинского факультета, Харьковский национальный университет им. В. Н. Каразина, пл. Свободы, 6, г. Харьков, Украина, 61077

E-mail:kozlov@karazin.ua

УДК 612.111: 612.135

DOI: $10.15587 / 2313-8416.2014 .35085$

\section{К ОБЪЯСНЕНИЮ МЕХАНИЗМА ВЛИЯНИЯ СДВИГОВОГО НАПРЯЖЕНИЯ НА ВЯЗКОСТНЫЕ ПАРАМЕТРЫ КРОВИ В СОСУДАХ МАЛОГО ДИАМЕТРА}

\section{(С) Л. Н. Катюхин}

В работе приводятся данные экспериментального подтверждения и физиологическое объяснение феномена Фареуса-Линдквиста в капиллярах, используя анализ профилей осмотической деформируемости красных клеток крови. Показано дозозависимое изменение деформируемости эритроцитов в стадии изотропной сферы при формировании искусственных водных пор (нистатин) и закупорке $\left(\mathrm{PbCl}_{2}\right)$ имеющихся. Сигма-эффект снижения гематокрита и вязкости в сдвиговом потоке крови через сосуды малого диаметра вызывается обменом жидких фаз между эритрочитом и плазмой Ключевые слова: сигма-эффект, вязкость, эритрочиты, деформируемость, водные поры, напряжение сдвига

It is proposed a physiological and experimentally confirmed explanation of Fåhraeus-Lindqvist-effect in capillaries using the profile analyses of osmotic deformability of red blood cells. It was shown the dosedependent change of the erythrocytes deformability in the stage of isotropic spheres after forming artificial water pores (nystatin) and occlusion $\left(\mathrm{PbCl}_{2}\right)$ of available pores. The Sigma-effect reducing of hematocrit and viscosity in a shear flow of blood through the vessels of a small diameter was conditioned by the interchange of liquid phase between the erythrocyte and the plasma

Keywords: sigma-effect, viscosity, erythrocytes, deformability, water pores, shear stress 